\title{
Bonson, Sury-Le-Comtal, Saint-Marcellin-en-Forez
}

ZAC des Plaines

\section{Vincent Georges}

\section{(2) OpenEdition \\ Journals}

Édition électronique

URL : http://journals.openedition.org/adlfi/1774

ISSN : 2114-0502

Éditeur

Ministère de la culture

Référence électronique

Vincent Georges, «Bonson, Sury-Le-Comtal, Saint-Marcellin-en-Forez », ADLFI. Archéologie de la France - Informations [En ligne], Rhône-Alpes, mis en ligne le 01 mars 2008, consulté le 19 avril 2019. URL:

http://journals.openedition.org/adlfi/1774

Ce document a été généré automatiquement le 19 avril 2019

(C) Ministère de la Culture et de la Communication, CNRS 


\title{
Bonson, Sury-Le-Comtal, Saint- Marcellin-en-Forez
}

\author{
ZAC des Plaines
}

Vincent Georges

\section{Identifiant de l'opération archéologique : 9925}

Date de l'opération : 2008 (EV)

1 L'aménagement de la ZAC des Plaines, réparti sur les trois communes de Bonson, Sury-leComtal et Saint-Marcellin-en-Forez, a occasionné une première opération de diagnostic (tranche 1). Elle a porté sur une surface d'environ 25 ha qui couvre essentiellement une vieille terrasse alluviale attenante à la plate-forme tertiaire de la plaine du Forez. Pour les périodes récentes, il a pu être observé des indices d'un réseau parcellaire probablement gallo-romain ainsi qu'une petite nécropole antique avec dépôts de crémations peut-être d'origine familiale. Cette dernière se situe aux abords de la zone péri-urbaine de la commune actuelle de Bonson. Le mobilier issu des dépôts de crémations repose sur un élément de datation compris entre la fin du $\mathrm{I}^{\text {er }}$ s. apr. J.-C. et le II ${ }^{\mathrm{e}}$ s. apr. J.-C. Il s'agit d'une coupe à pied en sigillée à décor à feuilles d'eau. Une fenêtre ouverte autour des incinérations avec décapage de la terre végétale a permis de délimiter un espace funéraire cohérent qui comprenait cinq à six fosses très rapprochées, situées à moins de deux mètres les unes des autres. Le décapage a également permis de mettre en évidence un lambeau de niveau de sol caractérisé par un épandage de fragments de céramiques brûlées probablement issus d'un bûcher. Un fragment brûlé de buis travaillé (couvercle de pyxide) fait partie des éléments découverts comme des résidus variés de vaisselles brûlés. Un seul dépôt d'incinération se trouvait partiellement à l'intérieur d'un vase ovoïde placé en fosse. Les charbons de bois issus des résidus de crémation indiquent la présence de sapin blanc, de chêne et de nephrun en plus des restes de récipients en buis. Le sapin blanc pourrait indiquer la présence d'un cercueil ou de simples planches placées sur le bûcher. 
2 Une série de trois autres études anthracologiques réalisées dans le cadre de ce diagnostic apporte des indices sur des résidus de combustion anthropiques. Sur le plan environnemental, ils indiquent la présence d'une chênaie plus ou moins fermée sur la vieille terrasse de la Loire notamment à l'époque antique. La présence de fragments de silex tertiaires locaux brûlées dans un des horizons à charbons de bois permet d'évoquer la période du Néolithique en l'attente de données ${ }^{14} \mathrm{C}$. Le ruisseau du Malbief artificiellement encaissé sur les limites de parcelles draine ce secteur fortement humide avec de faibles dépôts en matières ferro-manganèses.

INDEX

Thèmes : anthracologie, bûcher, céramique, charbon de bois, incinération, nécropole, nécropole à incinération, parcellaire, sépulture collective, sol, urne, vaisselle

Index chronologique : Antiquité, Empire romain, Ier siècle apr. J.-C., IIe siècle apr. J.-C., Néolithique

operation Fouille d'évaluation (EV)

Index géographique : Rhône-Alpes, Loire (42), Bonson

\section{AUTEUR}

VINCENT GEORGES

Inrap 